\title{
Chinko/Mbari drainage basin represents a conservation hotspot for Eastern Derby eland in Central Africa
}

\author{
Karolína Brandlová1 ${ }^{1}$ | Markéta Gloneková ${ }^{1}$ | Pavla Hejcmanová1 | \\ Pavla Jůnková Vymyslická $^{1}$ | Thierry Aebischer ${ }^{2}$ | Raffael Hickisch ${ }^{3}$ | David Mallon ${ }^{4}$
}

${ }^{1}$ Faculty of Tropical AgriSciences, Czech University of Life Sciences Prague, Praha 6, Czech Republic

${ }^{2}$ Department of Biology, University of Fribourg, Fribourg, Switzerland

${ }^{3}$ Chinko Project, Operations, Chinko, Bangui, Central African Republic

${ }^{4}$ Co-Chair, IUCN/SSC Antelope Specialist

Group and Division of Biology and

Conservation Ecology, Manchester

Metropolitan University, Glossop, UK

\section{Correspondence}

Karolína Brandlová

Email: karolina@derbianus.cz

Funding information

Czech University of Life Sciences Prague, Grant/Award Number: 20135010, 20134220; Faculty of Tropical AgriSciences, Grant/Award Number: IGA 20165010, 20165017; Postdok ČZU, Grant/Award Number: CZ.1.07/2.3.00/30.0040

\begin{abstract}
One of the largest of antelopes, Derby eland (Taurotragus derbianus), is an important ecosystem component of African savannah. While the western subspecies is Critically Endangered, the eastern subspecies is classified as least concern. Our study presents the first investigation of population dynamics of the Derby eland in the Chinko/Mbari Drainage Basin, Central African Republic, and assesses the conservation role of this population. We analysed data from 63 camera traps installed in 2012. The number of individuals captured within a single camera event ranged from one to 41 . Herds were mostly mixed by age and sex, mean group size was 5.61, larger during the dry season. Adult (AD) males constituted only $20 \%$ of solitary individuals. The overall sex ratio (M:F) was $1: 1.33$, while the $A D$ sex ratio shifted to 1:1.52, reflecting selective hunting pressure. Mean density ranged from 0.04 to 0.16 individuals $/ \mathrm{km}^{2}$, giving an estimated population size of 445 1,760 individuals. Chinko harbours one of the largest documented populations of Derby eland in Central Africa, making Chinko one of its potential conservation hotspots.
\end{abstract}

\section{Résumé}

Une des plus grandes antilopes, l'éland de Derby (Taurotragus derbianus) est une composante importante de l'écosystème de savane africaine. Alors que la sous-espèce de l'Ouest est "En danger critique d'extinction", la sous-espèce de l'Est est classée comme "Préoccupation mineure". Notre étude présente la première enquête sur la dynamique de la population de l'éland de Derby dans le bassin de drainage de Chinko/Mbari, en République Centrafricaine, et elle évalue le rôle de cette population pour la conservation. Nous avons analysé les données provenant de 63 pièges photographiques installés en 2012. Le nombre d'individus capturés par une seule caméra allait de 1 à 41. Les troupeaux étaient en général mélangés quel que soit l'âge et le sexe, et la taille moyenne d'un groupe était de 5.61 individus, plus grand en saison sèche. Les mâles adultes ne représentaient que $20 \%$ des animaux solitaires. Le sexratio global (M/F) était de $1 / 1.33$, alors que le sex-ratio des adultes passait à $1 / 1.52$, reflétant l'impact de la pression sélective de la chasse. La densité moyenne allait de 0.04 à 0.16 individu/ $\mathrm{km}^{2}$, ce qui donne une population estimée entre 445 et 1,760 individus. Chinko accueille une des plus grandes populations d'élands de Derby connues en Afrique centrale, ce qui en fait un des hauts lieux potentiels de leur conservation.

KEYWORDS

antelope, Central African Republic, Giant eland, Tragelaphus derbianus, trophy hunting 


\section{1 | INTRODUCTION}

Despite being one of the largest antelopes, with males reaching $>900 \mathrm{~kg}$ (Planton \& Michaux, 2013), the main source of information about Derby eland ecology is an unpublished MSc. thesis (BroJørgensen (1997). Derby or Giant eland (DE, Tautrotragus derbianus, syn. T. derbianus) (Wilson \& Reeder, 2005), is a savannah-woodland dwelling antelope inhabiting Western and Central Africa. It plays a crucial role in savannah ecosystem function as a browser and as prey for large predators (Bro-Jørgensen, 1997). The DE also has an important economic role, especially through tourism and sport hunting. Its massive horns make it one of the most sought-after trophies in Africa (Angwafo, Nji, Mbida, \& Wiegleb, 2008). The Western subspecies ( $T$. d. derbianus) is assessed as Critically Endangered (IUCN, 2008a) and is the subject of a long-term conservation programme in Senegal (Brandlová et al., 2013; Koláčková, Hejcmanová, Antonínová, \& Brandl, 2011; Zemanová, Bolfíková, Brandlová, Hejcmanová, \& Hulva, 2015). The eastern subspecies (Tautrotragus derbyanus gigas) has until recently been listed as least concern (IUCN, 2008b) but a revised assessment as Vulnerable has been submitted.

In West and Central Africa, populations of large mammals collapsed in protected areas between 1970 and 2005 by $65 \%-85 \%$ (Bouche et al., 2010; Craigie et al., 2010), and identifying drivers of these declines is urgent (Scholte, 2011). Elephants in the region have been decimated due to the ivory trade and other large mammals are declining because of overhunting for bushmeat, increased cattle grazing resulting in transmission of disease and outcompeting wildlife for resources, and habitat changes due to shifts in rainfall patterns (Bouche et al., 2012). After the rinderpest outbreak of 1983-1984 the DE population declined by an estimated 60-80\%, but later recovered, particularly in Central African Republic (CAR). East (1999) estimated the DE population at 15,000-20,000 (c. 12,500 in CAR, the rest in Cameroon and South Sudan) and said the species was likely declining. Contrastingly, Chardonnet and Chardonnet (2004) reported DE as "increasing" in CAR, without further explanation. Recent counts in some CAR protected areas and hunting zones reported stable or slightly increasing populations of DE (Bouche et al., 2010; Fay, Elkan, Marjan, \& Grossmann, 2007); however, absolute numbers are very low (see further). The largest population, c. 4,125 individuals, was in the CAR in the BaminguiBangoran National Park (NP), Manovo-Gounda St. Floris NP and surrounding hunting reserves (Bouche et al., 2010; Graziani \& d'Alessio, 2004). The second most important population was recorded in three NPs (Bouba Ndjida, Bénoué and Faro) in Northern Cameroon, which are surrounded by hunting areas and transboundary with the Sena Ouara protected area in Chad. Although population estimates suggested 2,000-3,000 individuals in northern Cameroon (Bro-Jørgensen, 1997), only 200 individuals were spotted there during aerial counts (Omondi, Bitok, Tchamba, Mayienda, \& Lambert, 2008). Finally, an aerial count in Southern NP in South Sudan confirmed the presence of 100-200 individuals of DE (Fay et al., 2007).
DE could be a potentially key species for conservation in the area provided that setting of trophy hunting quotas is based on population dynamics and that some of the revenue reaches the local level.

The aim of our investigation was to carry out the first evaluation of population characteristics of the DE population in the Chinko Project Area (called hereafter Chinko) in Chinko/Mbari Drainage basin in south-eastern CAR. Legal hunting in this area was controlled by one safari provider. Based on camera trap data we aimed (i) to identify DE population characteristics in the dry and wet seasons; (ii) to provide an index of DE population size and density.

\section{MATERIAL AND METHODS}

\subsection{Study area}

Chinko is located in south-eastern CAR $\left(6.3^{\circ} \mathrm{N}, 24.0^{\circ} \mathrm{E}\right)$, covers $17,600 \mathrm{~km}^{2}$, and is part of a wilderness of more than $85,000 \mathrm{~km}^{2}$ (Figure 1). It represents a natural mosaic of woody Sudanese and Sudano-Guinean savannah and Congolese lowland rainforest without permanent human settlements or agricultural activities. Average annual precipitation is $1,200-1,600 \mathrm{~mm}$ (Roulet, Pelissier, Patek, Beina, \& Ndallot, 2007). The wet season occurs between April and October and is followed by a dry season. More than 82 species of mammals have been documented in Chinko so far, including African forest elephant (Loxodonta cyclotis), African wild dog (Lycaon pictus), leopard (Panthera pardus) and lion (Panthera leo). Large antelopes besides the DE are represented by lelwel hartebeest (Alcepahus buselaphus lelwel), roan antelope (Hippotragus equinus), defassa waterbuck (Kobus defassa) and bongo (Tragelaphus eurycerus).

The area was administered in cooperation with the hunting company Central African Wildlife Adventures (CAWA), then converted into a nature conservation area under the management of the Chinko Project (www.chinkoproject.com). Since 2014, Chinko has been a member of the African Parks Network (www.africanparks.org). In Chinko, selective trophy hunting took place in a defined zone from December to May. Between 2007 and 2012, the hunting quotas for DE were assigned by the authorities in Bangui and professional hunters on the ground. Since 2013, quotas have been based on the first field observations assuming a minimum population of 350 individuals and a quota of $6.4 \%$, taking into account the $10 \%$ incidental off-take considered sustainable for common eland (Taurotragus oryx) (Caro, Young, Cauldwell, \& Brown, 2009). This resulted in a hunting quota of 22.4 individuals per year. There were 24 individuals legally hunted in the season before our study (2010/2011) and 21 in the study season (2011/2012), all within the Chinko hunting blocks. Six of these individuals were hunted in the camera trap study area and another three individuals just outside $(<10 \mathrm{~km})$.

Nomadic herdsmen from Sudan have traditionally passed through the area and since 2011 have been seasonally present with increasing numbers and frequency. As well as grazing livestock, herders apparently poach wildlife as a valuable food resource - selectively 


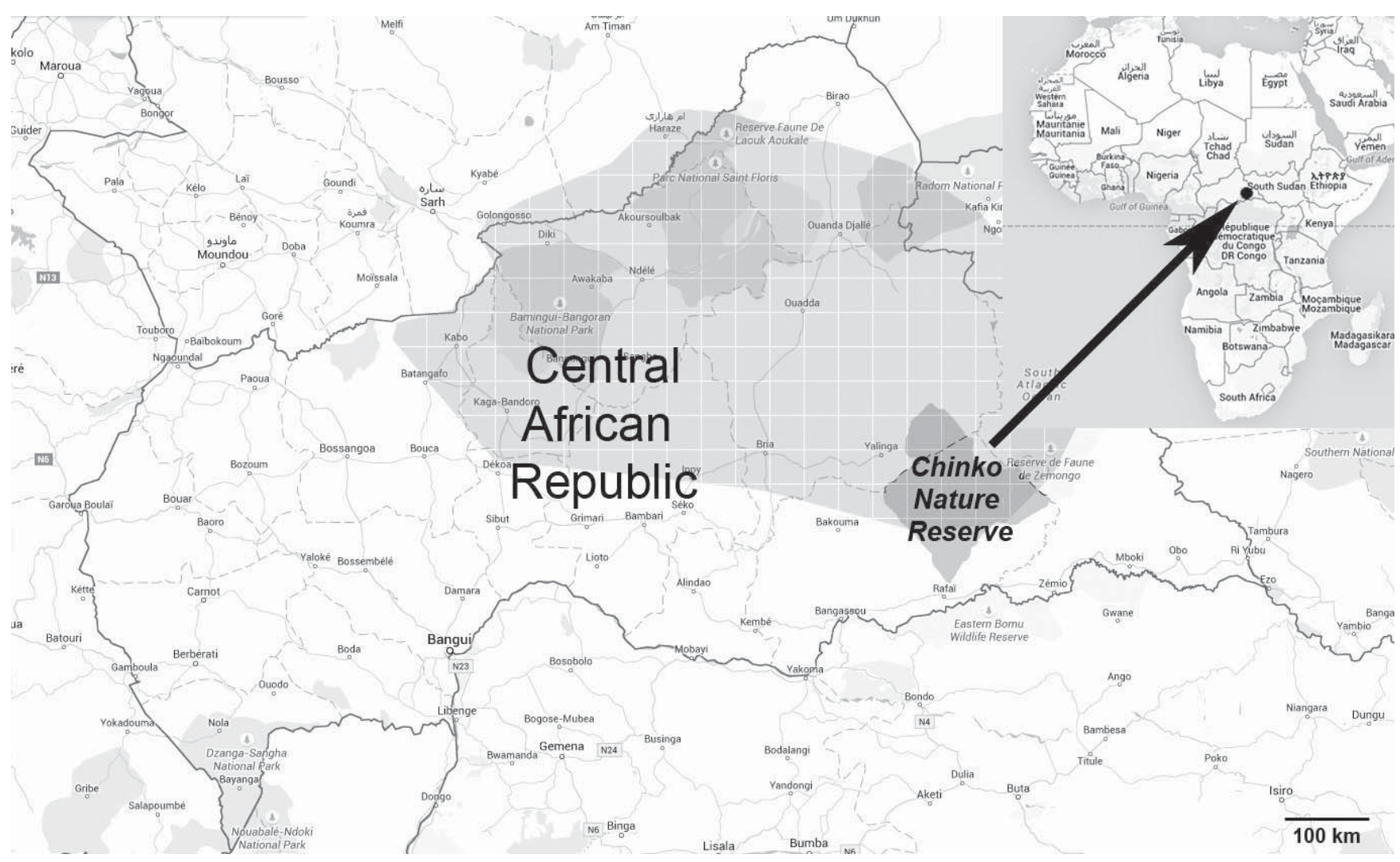

FIGURE 1 Distribution of Eastern Derby eland in the Central African Republic (light grey) and location of the study area (dark grey)

DE and African buffalo (Syncerus caffer; T. Aebischer personal observation). Furthermore, their livestock comprising thousands of cattle, donkeys, goats and sheep interact with wildlife at salt licks and water points and may transmit diseases.

\section{2 | Methods}

Camera traps were placed in the north-eastern part of Chinko (Figure 1) in woody savannah, at altitudes between 567 and $721 \mathrm{~m}$. Two types of camera traps were used: Bushnell 119436 Trophy Cam (Bushnell Outdoor Products, France) and Reconyx HC500 HyperFire Semi-Covert IR (Reconyx Inc., Wisconsin, USA). Photos were taken by activation of motion sensors, every detection resulted in three consecutive pictures with a minimum interval between events of $1 \mathrm{~s}$. Infrared light was automatically activated in poor light conditions. The functioning of some cameras was compromised by a combination of events, including theft, leaking batteries, hyaena bites, fires, floods and falling trees. We finally used data from 63 camera traps functional in dry and wet seasons 2012. There were 47 camera traps functional during 22 days in the dry season (DRY, 1,034 trap-days) covering $667 \mathrm{~km}^{2}$, and 21 camera traps during 73 days in the wet season (WET, 1,533 trap-days) covering $385 \mathrm{~km}^{2}$. Five camera traps functioned during both DRY and WET. The other 15 camera traps were not included in the analyses because they worked for only a few days or not simultaneously with other camera traps. None of these 15 camera traps recorded DE.
We analysed all photos containing DE. When possible, we identified animals individually and/or determined the sex (male - M, female - F, unspecified - $U$ ) and age category (adult older than 2 years - AD, subadult, 1-2 years - SUB, juvenile up to 1 year - JUV) of each animal using external traits such as body size and horn size and shape. Individuals were recognized by the coat pattern, namely the white stripes unique to each animal (Brandlová et al., 2013). We assessed the resulting photos for left (L) and right (R) sides of animals separately, as in most cases it was not possible to assign both sides together.

We organized photos into camera events, defined as the time period containing all photos from the first approaching animal and to the last individual of a group. During a single event, camera traps therefore took photos constantly when animals were moving. All individuals recorded during one event were considered members of one herd. Assuming equal trapping probability for all age-sex classes, we calculated the number of individuals recorded during one camera event, average group size, M:F ratio, and number of SUB and JUV individuals and assigned the group types (mixed, unisex). The differences among group types and between DRY and WET were tested by nonparametric Mann-Whitney $U$ and Kruskal-Wallis tests, respectively, the latter followed by multiple comparisons of mean ranks of all groups. Statistical analyses were performed in STATISTICA 12 (StatSoft Inc., Tulsa, USA).

We estimated the birth season based on JUV horn size (horns are shorter than ears in individuals $<4$ months) (Antonínová, 2008). Given that eland females have one calf each year and assuming stationary age distribution and equal probability of sampling for all 
individuals we calculated vital rates of the DE population. Annual mortalities of selected age-sex classes were calculated from age-sex class ratios, based on the assumption that the number of calves born each year remains stable, as follows:

$$
\begin{aligned}
& M_{\text {anJUV }}=\left(N_{\text {JUV }}-N_{\text {SUB }}\right) / N_{\text {JUV }}, \\
& M_{\text {anSUB }}=N_{\text {SUB }} *\left(1-M_{\text {anJUV }}\right) / N_{\text {TOT }}, \\
& M_{\text {anADF }}=N_{\text {SUBF }} *\left(1-M_{\text {anJUV }}\right) / N_{\text {ADF }}, \\
& M_{\text {anADM }}=N_{\text {SUBM }} *\left(1-M_{\text {anJUV }}\right) / N_{\text {ADM }}
\end{aligned}
$$

where $M_{\text {anJUV }}, M_{\text {ansUB }}, M_{\text {anADF }}$ and $M_{\text {anADM }}$ represent annual mortality rate of JUVs, SUBs, AD females and AD males (in \%) and $N_{\text {JuV }}$, $N_{\text {SUB }}, N_{\text {SUBF }}, N_{\text {SUBM }}, N_{\text {ADF }}$ and $N_{\text {ADM }}$ represent number of recorded JUVs, SUBs, SUB females, SUB males, AD females and AD males, respectively. $N_{\text {TOT }}$ indicates total number of recorded $D E$.

To assess the influence of legal hunting on $M_{\text {anADM }}$, we added the number of hunted bulls ( $N_{\mathrm{HUN}}$ ) to the number of $A D$ bulls.

$$
M_{\text {anADM }}=N_{\text {SUBM }} *\left(1-M_{\text {anJUV }}\right) / N_{\text {ADM }}+N_{\text {HUN }}
$$

We are aware that some hunted males may be already recorded on the camera-traps and that this may artificially increase the number of males in the population, so it should be considered an extreme value.

Based on the assumption that one calf may be born per female per year, while the calf is reared only when its mother survives we calculated the breeding rate:

$$
\text { Breeding rate }(\%)=N_{J U V} / N_{\mathrm{ADF}} *\left(1-M_{\mathrm{anADF}}\right)
$$

Number of individuals of a specific sex was calculated as the sum of individuals with determined sex and the proportional number of individuals with undetermined sex within the same age category.

To index the abundance and density of DE in Chinko area we used two methods leading to (i) minimum abundance and density (MIN) and (ii) observed abundance and density (OBS). The MIN values represent the number of individuals which were individually identified or recorded during a single event. We counted individually identified animals and compared their number with the maximum number of individuals of the same age and sex category recorded during one camera event (Table 2). The higher number was taken as the MIN number of individuals of the age and sex category in the study area (MIN abundance). No individually identified animal was captured repeatedly. We therefore calculated OBS abundance, based on assumption that each individual DE was captured just once.

For the calculation of MIN DE population density, we used the MIN abundance per area covered by camera traps in the dry and wet season, respectively. OBS density was calculated from OBS abundance. Mean density (MIN and OBS) was further multiplied by the extent of the whole area suitable for DE and used for the index of total DE abundance in Chinko.

\section{3 | RESULTS}

Thirteen cameras of 63 captured DE (eight and five during DRY and WET, respectively). In total, 638 photos of DE were analysed (435 and 203 from DRY and WET, respectively) and arranged into 54 events (34 and 20 from DRY and WET, respectively).

We successfully identified 44 individuals of 128 (34\%) during DRY and two of 44 individuals (5\%) during WET. In total, 33 DE (six AD M, five SUB M, 12 AD F, six SUB F, seven JUV U) were identified from the right side and 15 (three $A D M$, four SUB $M$, seven AD F, one SUB F) from the left side. Only one individual was identified from both sides (AD F) as it turned in front of the camera trap during a single event.

Number of individuals captured within a single-camera event ranged from one to 41 . Solitary individuals were caught in 29 events (17 and 12 in DRY and WET, respectively). Both $M$ and $F$ of all age classes were caught alone, $A D M$ were only six of them.

From 25 events we identified five types of groups: females $(n=1)$, males $(n=1)$, calves $(n=1)$, female with calves $(n=1)$ and mixed groups $(n=14)$. For the other groups $(n=7)$, we could not identify agesex classes. Mean group size was $5.61 \pm 0.82$ SE (range 2-41) and differed by group type $(H(5, n=49)=32.326, p \leq .001)$, reaching the highest values in mixed groups. Group size differed between seasons $(U=546, Z=-2.035, p<.05)$, with larger groups during DRY (Table 1).

The overall sex ratio ( $M$ to $F$ ) was 1:1.33 (DRY 37:47, WET 9:14), AD sex ratio 1:1.52 (DRY 21:34, WET 4:4). The overall sex ratio would be less skewed if all nine hunted males were included (1:1.12). JUV individuals formed 15\% (16 records of 128 in DRY, and five of 44 in WET) of the population, SUB individuals $18 \%$ (27 records out of 128 in DRY, five of 44 in WET; Table 2). Given JUV horn size, births occurred October-December.

Annual mortality rate of JUV reached $54 \%$ and dropped in $A D$ to 19.6\%. Annual mortality was $9.6 \%$ and $36 \%$ for $A D F$ and $A D M$, respectively. Considering the six (nine) males legally hunted in the study area and in its close proximity, $A D M$ annual mortality decreased to $27 \%$ (24.5\%). However, this result combines data from different sources and should be interpreted with caution. Breeding rate was $82 \%$.

MIN number of individuals within the camera trap area corresponded to the size of the largest herd within each season (Table 2). In DRY, it was 41 individuals per $667 \mathrm{~km}^{2}$, setting MIN density at 0.061 individuals $/ \mathrm{km}^{2}$. In WET, eight individuals were recorded in $385 \mathrm{~km}^{2}$, so MIN density was 0.02 individuals $/ \mathrm{km}^{2}$. Mean MIN density was 0.0405 individuals $/ \mathrm{km}^{2}$.

Assuming that each individual was captured just once, the OBS abundance of DE was 128 individuals during DRY and 44 individuals during WET, resulting in OBS densities of 0.19 and 0.11 individuals $/ \mathrm{km}^{2}$, respectively. Mean OBS density was 0.16 individuals $/ \mathrm{km}^{2}$.

Given the total area of suitable habitat in Chinko $\left(11,000 \mathrm{~km}^{2}\right)$, the total number of DE in Chinko may be expressed as MIN 445 individuals (220-671) or OBS $1,760(1,210-2,090)$, respectively.

\section{4 | DISCUSSION}

Our study presents the first documentation of the DE population in south-eastern CAR, which represents a bridging area between the 
TABLE 1 Composition of the herds ( $>1$ individual) of Derby elands captured by camera traps in the Chinko area in Central African Republic in 2012

\begin{tabular}{|c|c|c|c|c|c|c|c|c|c|c|c|c|}
\hline Period & Event ID & $A D M$ & $A D F$ & $A D U$ & SUB $M$ & SUB F & SUB U & JUV M & JUV F & JUV U & U & Total \\
\hline \multirow[t]{11}{*}{ Dry } & 6 & 1 & 0 & 0 & 1 & 2 & 0 & 0 & 0 & 0 & 0 & 4 \\
\hline & 8 & 1 & 1 & 1 & 2 & 0 & 2 & 0 & 0 & 0 & 0 & 7 \\
\hline & 11 & 2 & 1 & 0 & 0 & 0 & 0 & 0 & 0 & 0 & 0 & 3 \\
\hline & 13 & 1 & 3 & 0 & 0 & 0 & 0 & 0 & 0 & 0 & 0 & 4 \\
\hline & 23 & 2 & 4 & 2 & 2 & 0 & 1 & 0 & 0 & 0 & 1 & 12 \\
\hline & 39 & 1 & 2 & 0 & 1 & 0 & 1 & 0 & 0 & 0 & 0 & 5 \\
\hline & 44 & 0 & 2 & 0 & 1 & 0 & 0 & 0 & 0 & 2 & 2 & 7 \\
\hline & 48 & 1 & 2 & 0 & 0 & 1 & 0 & 0 & 0 & 0 & 1 & 5 \\
\hline & 49 & 0 & 0 & 2 & 1 & 0 & 0 & 0 & 0 & 1 & 0 & 4 \\
\hline & 56 & 1 & 1 & 0 & 1 & 0 & 0 & 0 & 0 & 0 & 0 & 3 \\
\hline & 62 & 5 & 10 & 8 & 6 & 1 & 0 & 0 & 5 & 3 & 3 & 41 \\
\hline \multirow[t]{3}{*}{ Wet } & 22 & 1 & 1 & 1 & 0 & 2 & 0 & 0 & 2 & 0 & 0 & 7 \\
\hline & 53 & 0 & 1 & 1 & 0 & 0 & 0 & 1 & 0 & 1 & 4 & 8 \\
\hline & 65 & 1 & 0 & 1 & 0 & 1 & 0 & 0 & 0 & 1 & 0 & 4 \\
\hline Total & & 17 & 28 & 16 & 15 & 7 & 4 & 1 & 7 & 8 & 11 & 114 \\
\hline
\end{tabular}

AD, adult; SUB, subadult; JUV, juvenile; $M$, male; F, female; $U$, unknown.

NPs of northern CAR and the easternmost part of the distribution range of this species.

The camera trap survey benefited from the possibility of individual identification through unique white stripe patterns on the flanks of DE, similar to spotted or striped carnivores (Karanth \& Nichols, 1998; Karanth, Nichols, Kumar, \& Hines, 2006); however, the study design did not allow identification of both sides of an animal together as the camera traps were not paired (Marshal, 2016). We succeeded in identifying from one side photographs only 46 of 176 individuals (27\%). The low success was caused by the predominantly nocturnal activity of DE (K. Brandlová, unpublished data) when the stripes were not clearly visible, as reported by Jůnek, Jůnková Vymyslická, Hozdecká, and Hejcmanová (2015). Furthermore, we could not use capture-recapture methods (Borchers \& Efford, 2008), as none of the identified DE was spotted more than once. We are aware that some DE might have been captured repeatedly even if the quality of the photographs did not allow identification, which is the main source of overestimation of population size. On the other hand, it is likely that not all the animals were photographed during the study period, leading to underestimation.

It is generally stated that DE are gregarious and seldom dwell alone, except for solitary males (Planton \& Michaux, 2013). However, the number of solitary individuals formed a considerable part of all capture events (51\% and $60 \%$ in DRY and WET). Adult males which are generally considered the most solitary formed only $20 \%$ of recorded solitary individuals. However, DE frequently move and browse in a loose herd structure with long inter-individual distances (K. Brandlová, personal observation). Combined with screening from dense vegetation cover, the animals photographed alone did not imply that there were no other individuals out of reach of the camera. The higher proportion of solitary individuals during WET may reflect vegetation density decreasing visibility of animals. The visibility problem is supported by the fact that most of the solitary individuals were photographed during darkness. Together with the fact that mixed groups formed the most frequent type of group recorded it implies that $A D$ males may have been mostly accompanying herds of females and calves rather than wandering alone.

The mean herd size detected corresponded to the average herd size of 20-30 individuals reported by Planton and Michaux (2013). The largest herd in Chinko was recorded in March, a mixed herd containing all age and sex classes, in accordance with estimated reproductive cycle. Herd sizes in Chinko support the observations of Planton and Michaux (2013) that large herds are formed already in early dry season (December-January in Cameroon) and stay together until the rains (June), when they split into smaller groups of less than ten. A large mixed herd of 69 individuals was recorded by Renaud, Gueye, Hejcmanová, Antonínová, and Samb (2006) in Senegal during the peak dry season in May. According to Bro-Jørgensen (1997) in Cameroon large herds (even over 100 individuals) formed during late dry and early wet seasons.

In agreement with Bro-Jørgensen (1997), the social structure of the $D E$ in Chinko seems to respond to seasonal changes in vegetation, water availability and/or bushfires. The camera trap data suggest that DE move around in smaller herds during the wet season, which may further split by the end of wet season for the birth period, as the females generally give birth alone. The calves stay hidden for several weeks and then females with calves join together to form large herds, with calves concentrated into nursery groups. Calves are nursed up to 6 months (Hejcmanová et al., 2011).

The overall sex ratio and $A D$ sex ratio were skewed in favour of females. Increased skew may be induced by selective hunting (Planton \& Michaux, 2013). However, when the data were corrected to 
TABLE 2 Distribution of age-sex classes within herds of Derby elands captured by camera traps in the Chinko area, Central African Republic in 2012

\begin{tabular}{|c|c|c|c|c|}
\hline & \multicolumn{2}{|l|}{ Dry } & \multicolumn{2}{|l|}{ Wet } \\
\hline & $\begin{array}{l}\text { Number of animals } \\
\text { (of which ID R) }\end{array}$ & $\begin{array}{l}\text { Mean number } \\
\text { per event (range) }\end{array}$ & $\begin{array}{l}\text { Number of animals } \\
\text { (of which ID R) }\end{array}$ & $\begin{array}{l}\text { Mean number } \\
\text { per event (range) }\end{array}$ \\
\hline AD M & $21(5)$ & $1.5(1-5)$ & 4 & $1.00(1-1)$ \\
\hline AD F & 34 (14) & 2.125 (1-10) & 4 & $1.00(1-1)$ \\
\hline $\mathrm{AD}(\mathrm{M}, \mathrm{F}, \mathrm{U})$ & 76 (19) & $2.81(1-23)$ & 13 & $1.44(1-3)$ \\
\hline SUB M & $16(5)$ & $1.78(1-6)$ & $2(1)$ & $1.00(1-1)$ \\
\hline SUB F & $7(1)$ & $1.17(1-2)$ & 3 & $1.5(1-2)$ \\
\hline SUB (M, F, U) & $27(6)$ & $2.07(1-7)$ & $5(1)$ & $1.25(1-2)$ \\
\hline JUV M & $0(0)$ & 0 & 2 & $1.00(1-1)$ \\
\hline JUV F & $6(6)$ & $3.00(1-5)$ & $5(1)$ & $1.25(1-2)$ \\
\hline$J U V(M, F, U)$ & $16(6)$ & $2.67(1-8)$ & 10 & $1.43(1-2)$ \\
\hline Total & 128 (31) & $3.66(1-41)$ & $44(2)$ & $2.2(1-8)$ \\
\hline
\end{tabular}

Observed and minimal (in parentheses) numbers of animals in herds of Derby elands.

$A D$, adult; SUB, subadult; JUV, juvenile; $M$, male; F, female; U, unknown; ID R, number of animals identified from the right side.

exclude effect of selective hunting (i.e., legally hunted males were included to the dataset) the sex ratio remained skewed, suggesting either higher natural male mortality and/or selective poaching of $A D$ males. Male mortality is reportedly higher in both wild and captive environments (Brandlová et al., 2013; Bro-Jørgensen, 1997), and monitored populations in human care have male-biased sex ratios (1.04:1 in USA and 1.2:1 in Senegal) (Brandlová et al., 2013; McCaffree, 2011). The $A D$ sex ratio in a hunting concession in Cameroon was even more female biased (1:3.1) (Bro-Jørgensen, 1997) which suggest higher selective hunting pressure than in Chinko.

Although juveniles and subadults were not as numerous as in Cameroon where juveniles formed $25 \%$ and subadults $20 \%$ of the population (Bro-Jørgensen, 1997), Chinko population values are still higher than those from a semicaptive population in Senegal (juveniles $17 \%$, SUBs $13 \%$ ) which is still growing (deterministic population growth $\lambda=1.2$ ) (Brandlová et al., 2013).

Given a gestation length of about 9 months (Brandlová et al., 2013; McCaffree, 2011), the mating season of DE in Chinko occurs in January and February, as reported for Cameroon (DecemberFebruary; Planton \& Michaux, 2013). The mating season therefore corresponds with the formation of large herds where males compete for access to females (Bro-Jørgensen, 1997, K. Brandlová personal observation).

Parturition in DE is seasonal, mostly occurring at the end of wet season or start of dry season (October to December) (Brandlová et al., 2013), which is also the case in Chinko. In Senegal, the birth season extends until February, corresponding to the later start of the rains. A less clear seasonal pattern was recorded in the USA, with the majority of births during summer, however in captivity this was likely manipulated by breeding management (McCaffree, 2011).

Juvenile mortality in Chinko was relatively high (54\%) in comparison with known rates in the semicaptive population in Senegal (7\%) (Brandlová et al., 2013). Juvenile mortality is one of the most fluctuating vital rates, influenced by population density, stochastic environmental variation (Gaillard, Festa-Bianchet, \& Yoccoz, 1998) and predation. Given the high proportion of juveniles within the population and high breeding rate in Chinko, higher than in Cameroon 74\% (Bro-Jørgensen, 1997) and in Senegal 77\% (Brandlová et al., 2013), the high juvenile mortality rate does not seem to affect population growth negatively. High breeding rate could be a stronger determinant of population change than $A D$ mortality (Gaillard et al., 1998), which is relatively higher in Chinko (19.6\%) than in Senegal (5\%) (Brandlová et al., 2013).

Annual mortality of adult males in Chinko is higher than that of females, likely due to selective hunting. Given that male mortality may be naturally higher than female mortality (Brandlová et al., 2013) and that hunting of adult males could alter the age-sex structure, specific attention should be paid to setting hunting quotas. In Chinko, the number of legally hunted males decreased in the years following the study period in an attempt to reduce potential negative effects of hunting. In 2013/2014, only five DE bulls were legally hunted and only three in 2014/2015.

Maximum densities of a healthy undisturbed DE population were estimated at about 0.5 individuals $/ \mathrm{km}^{2}$ (Bro-Jørgensen, 1997), and up to 1.19 individuals $/ \mathrm{km}^{2}$ in intensively surveyed hunting zones in Northern CAR (Bouche et al., 2010). On the other hand, the semicaptive population of Western DE kept in the fenced Fathala reserve at a density of 1.51 individuals $/ \mathrm{km}^{2}$ is apparently over the carrying capacity of the environment and must be provided with supplementary feeding (Hejcmanová, Vymyslická, Žácková, \& Hejcman, 2013).

Both MIN and OBS population densities in Chinko were lower during WET than during DRY. We attribute this difference to a lower detection rate during WET due to vegetation cover. OBS population density in Chinko corresponds to the 0.15-0.3 individuals/ $\mathrm{km}^{2}$ reported by Planton and Michaux (2013); however, the MIN 
density is far lower, comparable with the densities reported from other suitable habitats. Bro-Jørgensen (1997) in Boumedjé hunting concession observed $68 \mathrm{DE}$ in $970 \mathrm{~km}^{2}$, for example 0.07 individuals $/ \mathrm{km}^{2}$. Densities of 0.07 and 0.09 individuals $/ \mathrm{km}^{2}$ were reported during aerial counts in 1991 and 1998 and ranged from 0.002 to 0.10 individuals $/ \mathrm{km}^{2}$ in 2005 in protected and hunting areas in northern CAR (Bouche et al., 2010). Omondi et al. (2008) reported 0.08 individuals $/ \mathrm{km}^{2}$ in Bouba-Ndjida NP and 0.003 individuals $/ \mathrm{km}^{2}$ in Faro NP, and (Fay et al., 2007) 0.006 individuals $/ \mathrm{km}^{2}$ in Southern NP in South Sudan. However, these low estimates were derived from aerial surveys, and not adjusted for undercounting resulting from low detection rates in thick vegetation.

Derby eland population size estimates from camera-traps were higher than those from field observations used to set hunting quotas. Despite this, hunting apparently affected the observed sex ratio, which may be also a consequence of poaching. The increasing levels of poaching in Chinko should be considered when reassessing quotas in future.

Chinko may hold $10 \%-25 \%$ of DE in CAR, taking into consideration the different methods used to estimate population size. However, the population is assumed to be declining due to the numerous poaching incidents recorded since 2012 .

It is difficult to extrapolate the density figures from our survey widely, but given the area of suitable habitat in Chinko and the uninhabited eastern part of CAR, including Zemongo reserve with $8,000 \mathrm{~km}^{2}$ of woody savannah and Chinko Headwater with $18,000 \mathrm{~km}^{2}$ of woody savannah, this region potentially holds one of the largest populations of this species. Chinko should be therefore viewed as a key locality for DE conservation.

Overall DE numbers are far lower than those estimated by East (1999). Taking into account the political insecurity, and the likely DE population trend in Chinko, we urge the need for further promotion of anti-poaching and other conservation measures.

\section{ACKNOWLEDGEMENTS}

We are grateful to the family Mararv and collaborators of CAWA safaris who made it possible to execute the first scientific field work in the Chinko area namely Erik, Emelie, Charlotte, Roland and Gunnel Mararv and David Simpson. Special thanks go also to the professional hunters, trackers and guides of CAWA which not only generously tolerated field work but also assisted whenever possible. Special thanks goes also to the "Basler Stiftung für biologische Forschung," PANTHERA and a very supportive community of private persons and small companies in Switzerland that financially supported field work. We thank also to Derbianus Conservation NGO for providing research capacities. We are grateful to Kateřina Hozdecká for initial processing of photographs. This work was supported by the Czech University of Life Sciences Prague CIGA 20135010 and 20134220, and the Faculty of Tropical AgriSciences, grants IGA 20165010 and 20165017. PJV was supported by project Postdok ČZU (ESF and MEYS CZ.1.07/2.3.00/ 30.0040).

\section{REFERENCES}

Angwafo, T. E., Nji, A., Mbida, M. \& Wiegleb, G. (2008). Estimated minimum and maximum sustainable exploitation values for Derby eland and other big game in Benoue National Park, Cameroon. Nature \& Faune, 23, 27-31.

Antonínová, M. (2008). The breeding and management of small animal populations: Case study of Western giant eland (Taurotragus derbianus derbianus, GRAY 1847) in Senegal. Department of animal sciences and food processing in TS, Ph.D. thesis, Czech University of Life Sciences Prague, Institute of Tropics and Subtropics, Prague.

Borchers, D. L. \& Efford, M. G. (2008). Spatially explicit maximum likelihood methods for capture-recapture studies. Biometrics, 64, 377385.

Bouche, P., Mange, R. N. M., Tankalet, F., Zowoya, F., Lejeune, P. \& Vermeulen, C. (2012). Game over! Wildlife collapse in northern Central African Republic. Environmental Monitoring and Assessment, 184, 7001-7011.

Bouche, P., Renaud, P. C., Lejeune, P., Vermeulen, C., Froment, J. M., Bangara, A., ... Fay, M. (2010). Has the final countdown to wildlife extinction in Northern Central African Republic begun? African Journal of Ecology, 48, 994-1003.

Brandlová, K., Mallon, D., Hejcmanová, P., Regnaut, S., Jůnková Vymyslická, P., ... Ndiaye, S. (2013). Western Derby eland (Taurotragus derbianus derbianus) conservation strategy. Prague: Czech University of Life Sciences Prague.

Bro-Jørgensen, J. (1997). The ecology and behaviour of the Giant eland (Tragelaphus derbianus, Gray 1847) in the wild. Master's Thesis, University of Copenhagen, Copenhagen, Denmark.

Caro, T. M., Young, C. R., Cauldwell, A. E. \& Brown, D. D. E. (2009). Animal breeding systems and big game hunting: Models and application. Biological Conservation, 142, 909-929.

Chardonnet, B. \& Chardonnet, P. (2004). Antelope survey update. IUCN/ SSC Antelope Specialist Group Report n. 9. pp. 81.

Craigie, I. D., Baillie, J. E. M., Balmford, A., Carbone, C., Collen, B., Green, R. E. \& Hutton, J. M. (2010). Large mammal population declines in Africa's protected areas. Biological Conservation, 143, 22212228.

East, R. (1999). African antelope database. Gland, Switzerland and Cambridge, UK: IUCN/SSC Antelope Specialist Group.

Fay, M., Elkan, P., Marjan, M. \& Grossmann, F. (2007). Aerial surveys of wildlife, livestock, and human activity in and around existing and proposed protected areas of Southern Sudan, dry season 2007 (Phase I). Wildlife Conservation Society, Southern Sudan.

Gaillard, J.-M., Festa-Bianchet, M. \& Yoccoz, N. G. (1998). Population dynamics of large herbivores: Variable recruitment with constant adult survival. Trends in Ecology \& Evolution, 13, 58-63.

Graziani, P. \& d'Alessio, S. G. (2004). Monitorage radiotélémetrique de l'Eland de Derby (Tragelaphus derbyanus gigas) dans le Nord de la République Centrafricaine. In Programme regional ecofac composante zones cynegetiques villageoises (R.C.A.) (pp. 77). Roma: I.E.A. (Istituto di Ecologia Applicata).

Hejcmanová, P., Vymyslická, P., Koláčková, K., Antonínová, M., Havlíková, B., Stejskalová, M., ... Hejcman, M. (2011). Suckling behavior of eland antelopes (Taurotragus spp.) under semi-captive and farm conditions. Journal of Ethology, 29, 161-168.

Hejcmanová, P., Vymyslická, P., Žácková, M. \& Hejcman, M. (2013). Does supplemental feeding affect behaviour and foraging of critically endangered Western Giant eland in an ex situ conservation site? African Zoology, 48, 250-258.

IUCN (2008a). Tragelaphus derbianus derbianus. The IUCN Red List of Threatened Species. e.T22056A9354316. Retrieved from https://doi. org/10.2305/IUCN.UK.2008.RLTS.T22056A9354316.en. 
IUCN (2008b). Tragelaphus derbianus gigas. The IUCN Red List of Threatened Species. e.T22059A9354799. Retrieved from http://dx.doi.org/ 10.2305/IUCN.UK.2008.RLTS.T22059A9354799.en.

Jůnek, T., Jůnková Vymyslická, P., Hozdecká, K. \& Hejcmanová, P. (2015). Application of spatial and closed capture-recapture models on known population of the Western Derby eland (Taurotragus derbianus derbianus) in Senegal. PLoS ONE, 10(9), e0136525.

Karanth, K. U. \& Nichols, J. D. (1998). Estimation of tiger densities in India using photographic captures and recaptures. Ecology, 79, 28522862.

Karanth, K. U., Nichols, J. D., Kumar, N. S. \& Hines, J. E. (2006). Assessing tiger population dynamics using photographic capture-recapture sampling. Ecology, 87, 2925-2937.

Koláčková, K., Hejcmanová, P., Antonínová, M. \& Brandl, P. (2011). Population management as a tool in the recovery of the critically endangered Western Derby eland Taurotragus derbianus in Senegal, Africa. Wildlife Biology, 17, 299-310.

Marshal, J.P. (2016). Survival estimation of a cryptic antelope via photographic capture-recapture. African Journal of Ecology, 55, 21-29.

McCaffree, L. (2011). Eastern giant eland (Taurotragus derbianus gigas). San Diego, CA: International Studbook, San Diego Zoo's Safari Park.

Omondi, P., Bitok, E. K., Tchamba, M., Mayienda, R. \& Lambert, B. B. (2008). Total aerial count of elephants and other wildlife species in Faro, Benoue and Bouba Ndjidda national parks and adjacent hunting blocks in Northern Cameroon. Yaoundé: WWF.

Planton, H. P. \& Michaux, I. G. (2013). Traglephus derbianus Giant eland (Lord Derby's eland). In J. Kingdon \& M. Hoffmann (Eds.), Mammals of Africa. Volume VI: Pigs, hippopotamuses, chevrotain, giraffes, deer and bovids (pp. 186-190). London: Bloomsbury publishing.
Renaud, P. C., Gueye, M. B., Hejcmanová, P., Antonínová, M. \& Samb, M. (2006). Inventaire aérien et terrestre de la faune et relevé des pressions au Parc National du Niokolo Koba. Plan d'Urgence PNNK, rapport annexe A (pp. 74). Dakar: APF, DPNS.

Roulet, P. A., Pelissier, C., Patek, G., Beina, B. \& Ndallot, J. (2007). Projet Zemongo - un aper cu du contexte ecologique et de la pression anthropique sur les ressources naturelles de la reserve de faune de Zemongo. pp. 56.

Scholte, P. (2011). Towards understanding large mammal population declines in Africa's protected areas: A West-Central African perspective. Tropical Conservation Science, 4, 1-11.

Wilson, D. E. \& Reeder, D. A. M. (2005). Mammal species of the world: A taxonomic and geographic reference. Johns Hopkins University Press.

Zemanová, H., Bolfíková, B. Č., Brandlová, K., Hejcmanová, P. \& Hulva, P. (2015). Conservation genetics of the Western Derby eland (Taurotragus derbianus derbianus) in Senegal: Integration of pedigree and microsatellite data. Mammalian Biology-Zeitschrift für Säugetierkunde, 80, 328-332.

How to cite this article: Brandlová K, Gloneková M, Hejcmanová $\mathrm{P}$, et al. Chinko/Mbari drainage basin represents a conservation hotspot for Eastern Derby eland in Central Africa. Afr J Ecol. 2018;56:194-201.

https://doi.org/10.1111/aje.12431 